\title{
Evaluation and application of the optical image profiler (OIP) a direct push probe for photo-logging UV-induced fluorescence of petroleum hydrocarbons
}

\author{
Wesley McCall ${ }^{1}\left[\right.$ - Thomas M. Christy ${ }^{1} \cdot$ Daniel A. Pipp ${ }^{1} \cdot$ Ben Jaster $^{1} \cdot$ Jeff White $^{2} \cdot$ James Goodrich $^{3} \cdot$ John Fontana $^{4}$. \\ Sheryl Doxtader ${ }^{5}$
}

Received: 20 September 2017 / Accepted: 22 March 2018 / Published online: 17 May 2018

(c) The Author(s) 2018

\begin{abstract}
The presence of free phase petroleum fuels in the subsurface (often called light nonaqueous phase liquids/LNAPL) is a hazard in almost every town and city in the modern world. Leaking underground storage tanks and the resulting contamination and hazards have proven to be a challenge to investigate and remediate. One issue is adequately characterizing the presence and spatial extent of LNAPLs in the subsurface. Experience has shown that conventional soil coring methods and groundwater monitoring methods are fraught with limitations that can lead to significant errors in the estimation of the amount and spatial distribution of LNAPLs in the subsurface. This leads to the development of inaccurate conceptual site models and costly errors in remedial actions. A new direct push logging tool, the optical image profiler (OIP), has been developed to obtain high resolution site characterization data to more accurately define the presence and extent of LNAPLs in unconsolidated materials. The OIP system uses a downhole ultraviolet light-emitting diode to induce fluorescence of fuel LNAPL. A small complimentary metal-oxide-semiconductor camera mounted inside the probe behind a sapphire window captures photographic images of visible range fluorescence as the probe is advanced by direct push methods. In situ images of subsurface fuel fluorescence have not previously been available to the investigator and may further the understanding of LNAPL behavior. The OIP software also provides a log of percent area fluorescence (\%AF) based on analysis of the images. An electrical conductivity (EC) dipole on the probe provides a log of bulk formation EC that is often a good indicator of formation lithology. The information presented here explains the basic design and operation of the OIP system in the field. Bench tests confirm the capability of the OIP system to detect a range of petroleum fuels. Field studies with the tandem EC and \%AF logs are used to identify LNAPL and its migration pathways in the subsurface. These capabilities can improve the management and remediation of LNAPL-impacted sites and reduce long-term costs associated with cleanup and closure.
\end{abstract}

Keywords Optical image profiler (OIP) · UV-induced fluorescence · Petroleum hydrocarbons · Direct push · Electrical conductivity(EC) $\cdot$ Photo-logging $\cdot$ LIF $\cdot$ UVOST $\cdot$ LNAPL

Electronic supplementary material The online version of this article (https://doi.org/10.1007/s12665-018-7442-2) contains supplementary material, which is available to authorized users.

Wesley McCall

mccallw@geoprobe.com

1 Geoprobe Systems, Salina, KS, USA

2 Iowa Department of Natural Resources/UST Section, Des Moines, IA, USA

3 VJ Engineering, Iowa City, IA, USA

4 Vista GeoScience, Denver, CO, USA

5 Remediation and Redevelopment Division, Michigan Department of Environmental Quality, Jackson, MI, USA

\section{Introduction}

One of the earliest works relative to contamination of groundwater by petroleum fuels was that of Williams and Wilder (1971) where free phase gasoline was present in the subsurface due to a product pipeline leak near the Pollock groundwater well field in Los Angeles, California. As the environmental industry developed, it became evident that leaks from petroleum underground storage tanks (UST), located in almost every town and city in the developed world, were widespread (EPA 1990; CLAIRE 2014). Petroleum fuels are typically lighter than and immiscible with water. Thus, fuels released from USTs often form light nonaqueous 
phase liquids (LNAPL) in the subsurface (Mercer and Cohen 1990). Guidance for the investigation and remediation of LNAPL contaminated facilities has been developed (EPA 1997; ASTM 2017a, b; ITRC 2009a, b). It became apparent that management of LNAPL contaminated sites was a challenge not easily nor quickly addressed and investigation and remediation of these sites may continue for 10-20 years and often longer (Suthersan et al. 2015). The development of methods and tools for accurate delineation of the presence and extent of LNAPLs is an ongoing process. A few tools for logging fuel fluorescence in unconsolidated formations have been developed (Bujewski and Rutherford 1997; Kram et al. 2004; St. Germaine 2011, 2012) and applied to assist with the delineation of LNAPL distribution.

This work reports on the development and application of a new optical logging tool, the OIP, that provides photographic images of hydrocarbon fuel fluorescence in the subsurface, a capability not previously available in the geoenvironmental industry. In a first phase of work with the OIP, bench studies were performed to test the response of the tool to mixtures of wet sand and various hydrocarbons. In the second phase of study described in this paper, the OIP was deployed at several contaminated sites. The OIP probe was driven into unconsolidated formations at these sites with a direct push machine. The purpose of this field testing was to obtain images and logs of actual contaminant fluorescence and to compare these results to the various other investigative methods used at those same sites.

\section{Background}

\section{UV-induced fluorescence and fluorescence logging}

Luminescence is the emission of light from any substance and can be divided into fluorescence and phosphorescence. Both phenomena occur by the release of a photon from a molecule as it changes from an electronically excited state to its ground state. Fluorescence is a short-lived process typically occurring on the time frame of approximately $10 \mathrm{~ns}$, while phosphorescence lifetimes are often milliseconds to seconds and even longer. Monoaromatic compounds like benzene, toluene, ethylbenzene and the xylenes (BTEX) as well as many polynuclear aromatic hydrocarbons $(\mathrm{PAH})$ such as naphthalene, anthracene and benzo-a-pyrene are fluorophores; that is, they fluoresce when exposed to light of a certain range of wavelength/frequency. The absorption and emission spectra of anthracene (Fig. 1) demonstrate the symmetry of the spectra exhibited by some fluorophores. It is also important to note that the emission spectra are generally the same, regardless of the excitation wavelength of the light. The physical process

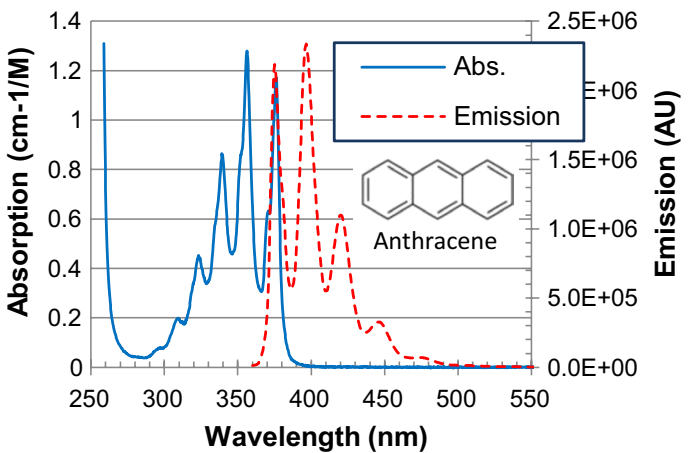

Fig. 1 Symmetrical absorption and emission spectra for anthracene (after Dixon et al. 2005; Berlman 1965) one of the fluorescent polynuclear aromatic hydrocarbons present in many petroleum fuels

of fluorescence was studied extensively by Alexander Jabłoński in the early to mid-1900s. The Jabłoński diagram (Fig. S1) is used to describe the changes in the electron state of a molecule that occurs during the absorption of energy, internal conversion and fluorescence that occurs in fluorophores (Lakowicz 1999).

The presence of PAHs such as naphthalene in petroleum fuels (EPA 1986) which fluoresce in the visible light range (Berlman 1965; Dixon et al. 2005) means that free-phase fuels can be detected by fluorescence methods. This lead to the development of several downhole probes equipped with a sapphire window coupled by fiber optics to an uphole nitrogen laser and spectrophotometer detector system (Bujewski and Rutherford 1997; Kram et al. 2004; ASTM 2017c) and a unique CPT system with a downhole Q-switched, multi-crystal Nd-YAG micro-laser design (Bloch et al. 1998). One of the most commercially successful laser-induced fluorescence (LIF) systems for fuel detection was developed by Dakota Technologies (St. Germaine 2011). This system uses a nitrogen laser-emitting light at $308 \mathrm{~nm}$ to induce fluorescence. A shorter wavelength laser would more efficiently induce fuel fluorescence, but the fiber optic materials used in the system absorb much of the shorter wavelength light (Karlitschek et al. 1998; St Germaine 2011; Bloch et al. 1998). Recent advances in the design of light-emitting diodes (LED) have led to the development of ultraviolet (UV) LEDs (Cooke 2010). During a similar time frame, the development of small complementary metal-oxide-semiconductor (CMOS) camera sensors has made it possible to capture good quality images on small digital devices like cell phones (Moynihan 2011). By combining these recent advances in LEDs and CMOS sensors with its experience in direct push logging technology (Christy et al. 1994; Christy 1996; McCall et al. 2006, 2009, 2014, 2017), Geoprobe has been able to develop the optical imaging profiler (OIP). 


\section{The OIP probe and logging system}

The OIP probe (model OP6560, Geoprobe Systems ${ }^{\circledR}$ ) (U.S. Patent Pending) is approximately $525 \mathrm{~mm}$ (20.75 in.) in length and has a maximum diameter of about $50 \mathrm{~mm}$ (2.0 in.) with a tapered square body design to enhance contact between the formation and probe (Fig. 2). The probe is equipped with a replaceable sapphire window on one side, having an optical opening of approximately $13 \mathrm{~mm}$. This window allows light from a 275-nm ultraviolet light-emitting diode (UV LED) (approx. 3-mW output) or visible light (vis) LED mounted inside the probe to illuminate the formation outside the window. Peak UV intensity is at the center of the window, and intensity drops to about $80 \%$ of peak intensity at the edge of the window. Fluorescence induced by the UV light (or reflected light from the vis LED) passes back through the window to a small CMOS camera mounted inside the probe. The CMOS sensor is a Bayer mosaic sensor which excludes most UV wavelength light so that BTEX fluorescence in the UV range is not detected. Images are captured by the camera at a rate of 30 frames per second (fps), but only one image is saved in the log file for every $15 \mathrm{~mm}$ $(0.05 \mathrm{ft})$ of $\log$ depth. The images are $9.5 \mathrm{~mm} \times 7.0 \mathrm{~mm}$ in area with resolution of $640 \times 480$ pixels (approx. 0.3 megapixels). The images are analyzed at $30 \mathrm{fps}$ in the acquisition software with a two-stage digital filter (U.S. Patent Pending) based on the HSV (hue, saturation, value) color model (Agoston 2005). Light detected by the camera must meet specified HSV criteria to be identified as UV-induced fluorescent light emitted by hydrocarbon contaminants. The first stage filter sets a minimum brightness level, above this level the hue on a given pixel must fall in a specified blue range to be classified as fuel fluorescence. The second stage filter checks for high brightness, low color saturation pixels. Both filters are summed to determine the percent area (pixels) of each image where fluorescent light is detected. The averaged $\%$ area of fluorescence for all images analyzed over each $15 \mathrm{~mm}(0.05 \mathrm{ft})$ increment of log is plotted on the $\log$ graph. Of course, if there is no fluorescence the images are dark. The captured fluorescence and analyzed images are displayed on-screen as the probe is advanced, along with the EC and percent area of fluorescence (\%AF) logs (Fig. 3). When advancement is stopped to add another drive rod, the acquisition software automatically captures a still image of both UV-induced fluorescence and visible light. The operator also can stop probe advancement at any depth of interest and capture UV and visible light still images by pressing an icon on the software screen. Still images (Fig. 4) are typically more clear and sharp than images captured, while the probe is being advanced and may be more useful for understanding soil texture and contaminant distribution in the soil matrix. After the log is completed, the file may be reviewed in the log viewing software (Fig. 3). Each of the images captured during the log, including stills, may be reviewed along with the $\mathrm{EC}$ and \% $\mathrm{AF} \log$. The logs, with selected image, or individual images, may be exported and saved for use in reports or presentations.

A dipole electrical conductivity (EC) array is included near the bottom of the OIP probe (Fig. 2). The EC array provides a log of bulk formation EC. Under fresh water conditions, the EC $\log$ often is a good indicator of formation lithology. However, some clays exhibit low EC response (McCall et al. 2014), and brines or total dissolved solids, along with other factors, may influence the EC response (McCall et al. 2017). Targeted sampling should be used to confirm the EC log response and interpretation.

A trunk line, pre-strung through the drive rods, connects the downhole probe to the electronic interface (Fig. 2) at the surface which is used to operate the OIP system. A Field Instrument (model FI6000, Geoprobe Systems ${ }^{\circledR}$ ) provides power for
Fig. 2 Primary components and basic construction of the OIP probe (a). The electronic components required to perform OIP logging in the field (b). A portable generator is used to provide all the electrical power needed to run the system while logging

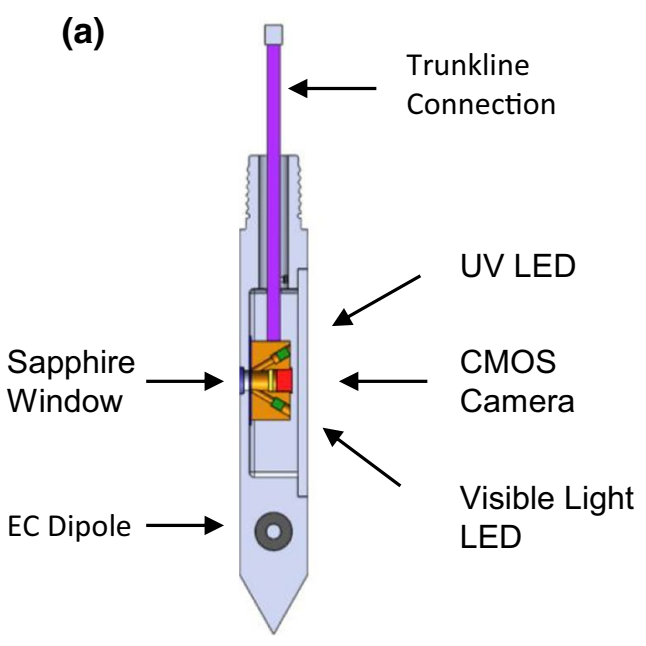

(b)

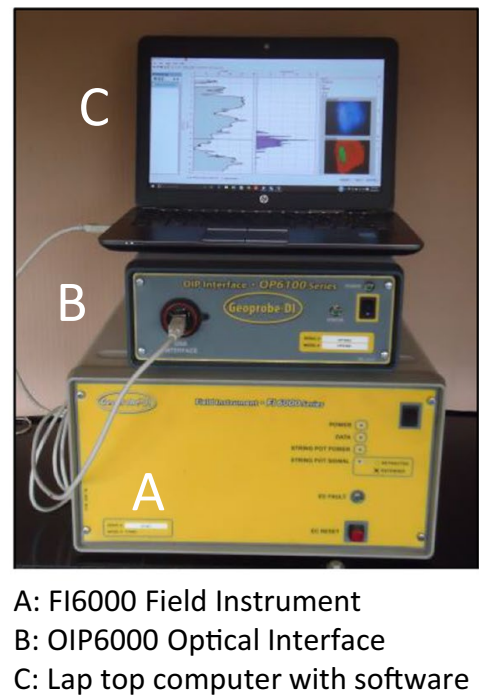


Fig. 3 Example of the log viewing software. Left to right: electrical conductivity and $\log$ of percent area of florescence (\% AF) observed in the images, and then the captured image of $\mathrm{UV}$-induced fluorescence and the analyzed image defining $29.7 \%$ area of fluorescence at $4.13 \mathrm{~m}$ depth in Kalona, Iowa $\log$ OIP03

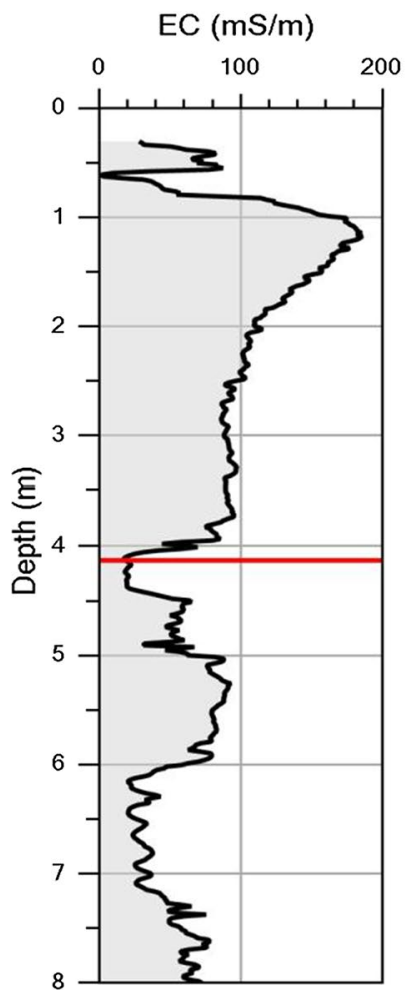

Fluorescence (\%)
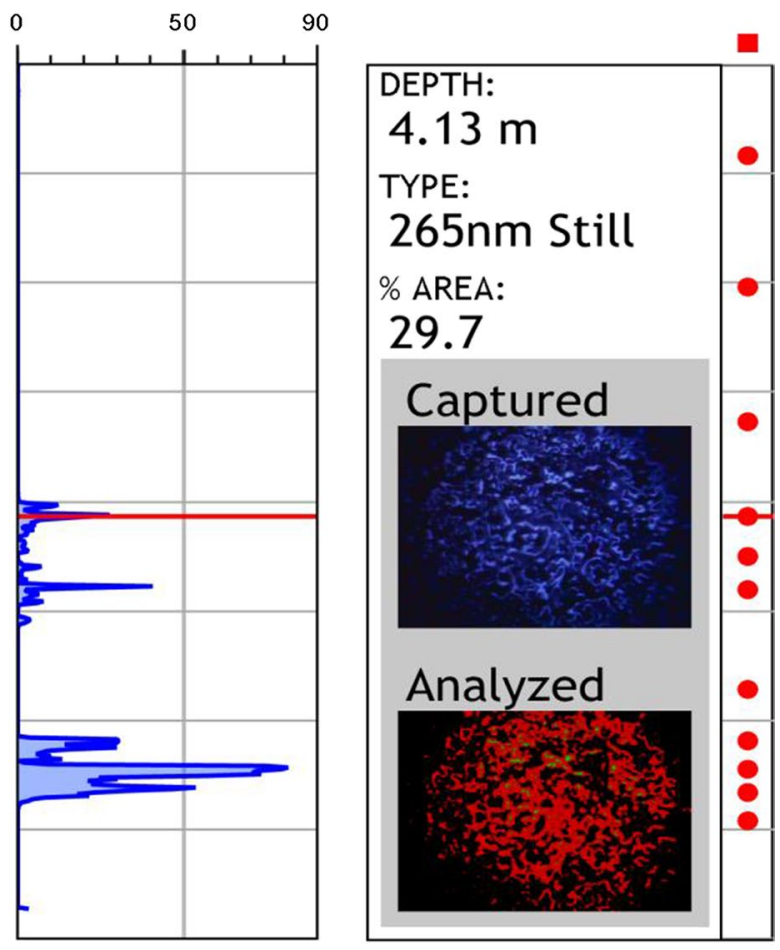

and acquires data from the EC dipole on the probe and from the string potentiometer mounted on the direct push machine. The string potentiometer is used to track the depth and rate of probe advancement. The FI6000 outputs multiple channels of data for presentation on a laptop computer via the acquisition software system. The OIP Interface (model OP6100, Geoprobe Systems ${ }^{\circledR}$ ) provides power to the two LEDs and the CMOS camera in the downhole probe and receives video image feed which is relayed to the laptop computer for analysis in the acquisition software. A summary of the field logging procedure and QA measures are provided below.

If present in the subsurface, some naturally occurring materials (e.g., seashells) and man-made materials (e.g., paper) may provide a false positive UV-induced fluorescence response (Bujewski and Rutherford 1997). Targeted visible light images (a capability only of the OIP system) may assist with determining a false positive condition for some interferants having a characteristic or contrasting color or physical form (e.g., seashells, caliche nodules). Alternately, targeted soil coring (ASTM 2017d) can quickly confirm if fluorescence is due to the presence of fuels or a false positive from natural or manmade materials causing interference.

\section{Bench studies}

\section{Bench study procedures}

To evaluate the level of fluorescence induced by the UV OIP probe, clean silica sand was spiked with measured amounts of known petroleum fuel products and crude oil. The fuels tested were fresh, commercially available products from a local distributor. The products tested include US unleaded regular gasoline and US on-road diesel fuel (diesel). In the USA, off-road diesel fuel (agricultural use) is taxed at a lower rate and is colored with a dye (for identification purposes) that significantly increases its fluorescence. The sand used for the bench tests is $95-99.5 \%$ silica/quartz (U.S. Silica, 2015) 20-40 grade (approximately $0.89-0.46 \mathrm{~mm}$ diameter) material. The clean sand was weighed on a scale (Ohaus model TS400D) in clean containers, and $10 \%$ water was added based on weight. A clean pipette (Eppendorf Reference) of appropriate size was then used to pipette a measured mass of fresh product into the weighed sand-water matrix. The mixture was 

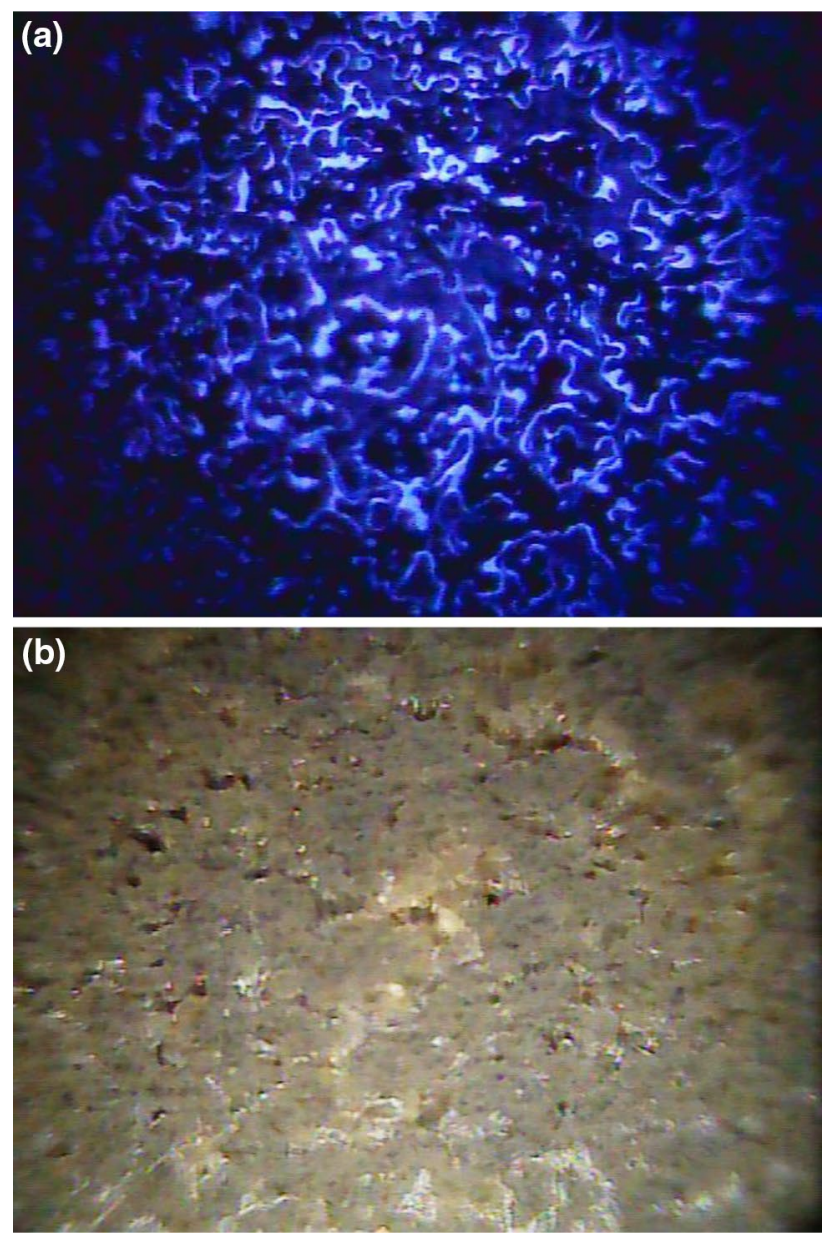

Fig. 4 Still images of gasoline fluorescence a showing blebs and ganglia in the water saturated formation matrix and $\mathbf{b}$ a visible light image captured simultaneously showing sand grains in a finegrained matrix. Both captured at a depth of $4.13 \mathrm{~m}$ in $\log$ OIP03 from Kalona, Iowa (see Fig. 3 above)

homogenized by gently stirring the sand-fluid mixture in the container. Product-sand samples were prepared fresh, immediately before each test. Product concentrations ranged from approximately $50 \mathrm{mg} / \mathrm{kg}$ to a maximum of about $250,000 \mathrm{mg} / \mathrm{kg}$ (Table S1).

The prepared product-sand samples were immediately tested on the OIP probe window using the OIP operating system described above. Sample aliquots were transferred to capsules that were placed over the window so that ambient light could not enter the optical cavity of the probe and interfere with the fluorescent light measurement. Each prepared sample was pressed firmly against the window to optimize contact between the sample matrix and the window and minimize void space. Images of the sample and resultant fluorescent light (Fig. S2) were captured as the string potentiometer was manually actuated at about $20 \mathrm{~mm} / \mathrm{s}$ over an approximate $600-\mathrm{mm}$ interval to simulate field procedure. Two or more tests were run on different sample aliquots for most concentration levels tested. The sapphire window was cleaned between each product concentration level, and a black box test was run to verify no cross contamination occurred.

\section{Bench study results}

Results from the bench tests of the unleaded gasoline, onroad diesel fuel and crude oil (Bemidji, MN) are summarized for review (Table S1). These tests were performed using a simplified matrix (clean silica sand $+10 \%$ moisture) to evaluate system performance under near ideal conditions. Results in the complex and heterogeneous matrix of natural soils and sediments may differ significantly from those observed during the bench tests. Indeed, fuels released to the environment and weathered over time may result in reduced levels and changes in hue of fluorescence due to the degradation and loss of the contained fluorophores (St. Germaine 2012). The results observed here will not be representative of highly weathered products. The data plots (Fig. 5) reveal that both unleaded gasoline and diesel fuel give a log-linear response over about an order of magnitude in concentration while the crude oil response is approximately log-linear over more than four orders of magnitude in concentration range. The diesel fuel response begins about an order of magnitude lower in concentration compared to gasoline. The increased sensitivity for diesel is expected due to diesel's higher concentration of fluorescent PAH compounds. Both gasoline and diesel approximate an asymptotic approach to the minimum and maximum axes of fluorescence $(0$ and $100 \%$, respectively) as seen for other downhole fluorescent logging methods (Bujewski and Rutherford 1997; Kram et al. 2004; St. Germaine 2011, 2012). All three products yielded correlation coefficients $\left(R^{2}\right) \geq 0.90$ for the log-linear portion of the response curves. These results indicate that the OIP probe and system are capable of detecting petroleum fuels over useful ranges of concentration and help to identify zones in the formation where petroleum LNAPLs are present. These data also indicate the use of image percent area fluorescence (\%AF) of the OIP image should provide a reasonable qualitative to semiquantitative indicator of petroleum LNAPL presence in the subsurface.

\section{Field studies}

\section{Field sites: background}

Results from three petroleum contaminated sites investigated with the OIP system are presented below. Each of the three sites has lingered in the investigation and remediation process in excess of 20 years, due partly to challenges in the regulatory and funding mechanisms for site assessment and 
Fig. 5 Plot of bench test results using the UV OIP probe to test different concentrations of two common petroleum fuels and one crude oil in a silica sand $+10 \%$ moisture matrix. Refined fuels showing a log-linear response over about an order of magnitude concentration range. A manually drawn curve for diesel indicates the asymptotic approach of the OIP fluorescence response at concentration extremes (near 0 and $100 \%$ fluorescence). Fluorescence response in complex and heterogeneous natural soils will vary. Two to five sample replicates averaged for each plotted data point $(\mathrm{Gas}=$ gasoline, Diesel $=$ U.S. on-road diesel fuel)

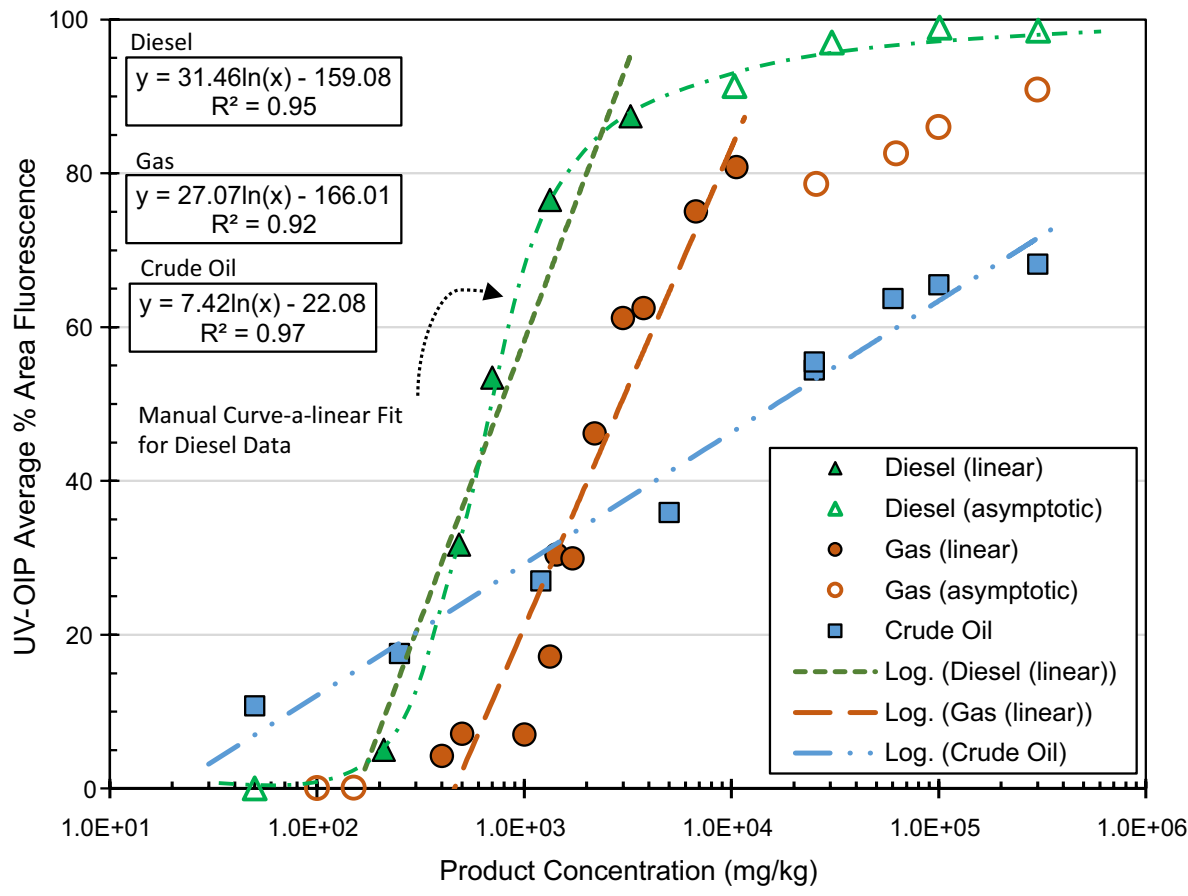

cleanup (White 2015). The difficult challenges of managing sites impacted by petroleum LNAPLs have received new interest with the understanding that definition of LNAPL distribution and its mobility in the subsurface are of significant importance (ITRC 2009a, b; Suthersan et al. 2015; NAVFAC 2017; ASTM 2017e).

At the Michigan UST site, both unleaded gasoline and diesel fuel were sold from 1963 to 2001. Six USTs with a total storage capacity of 116,000 L (29,000 US gallons) were removed from the site which is located in south central Michigan, USA. The site is underlain by glacial outwash and post glacial alluvium that consists of silty-clay to sand and gravel that may exceed $9 \mathrm{~m}(30 \mathrm{ft})$ in depth. Initial investigations identified both soil and groundwater impacts exceeding Michigan Part 213 criteria for multiple exposure scenarios. Based on these findings, the Michigan Department of Environmental Quality, Remediation and Redevelopment Division (MI DEQ RRD) scheduled a LIF survey using the Dakota Technologies UVOST system to evaluate the presence and distribution of LNAPL in the subsurface (Compliance Inc. 2016). Geoprobe was invited to run OIP logs colocated with the LIF logs at the Michigan facility in order to compare the OIP and LIF results. The site map (Fig. S3) shows the LIF log locations and site features.

The Grimm Oil Site in Kalona, Iowa, USA, is a former gasoline station which has undergone several episodes of assessment and corrective action. The site is located on alluvium of the English River in east-central Iowa, with deposits consisting of silty clays and seams of fine sand overlying Mississippian Age limestone and sandstone (Goodrich 2017; Bain 1895). In 1987, gasoline fumes were reported in a nearby residential basement during reconstruction of the foundation. The UST facility closed in 1994, and early investigations outlined the extent of the soil and groundwater contamination plumes (IDNR 2015). Under Iowa's risk-based corrective action program, the residential basement, a water main, and several sanitary sewer lines are designated as high risk and must undergo corrective action (IDNR 2017). To determine the extent and recoverability of LNAPL, the IDNR requested Geoprobe and the environmental contractor hired by the responsible party perform an OIP survey of the site. In 2 days, the investigation team utilized a direct push machine and OIP system to complete eighteen OIP logs across the contaminated area to a depth of approximately $8 \mathrm{~m}(26 \mathrm{ft})$. Site features and OIP log locations are displayed on the site map (Fig. S4).

A UST site located in northeastern Colorado operated as a gasoline station from circa 1960 until 1990 with four above ground storage tanks and one underground storage tank. A petroleum fuel release was initially confirmed in 1989 and since that time several site investigations and remedial actions have been undertaken and all storage tanks have been removed. Conditions at the site still exceed Colorado Tier 1 Risk-Based Screening Levels for the leachate to groundwater ingestion pathway and the groundwater ingestion exposure pathway (CDLE 2017). The site lies near the south edge of the lower Platte River alluvial aquifer in Morgan County, Colorado. The Pleistocene alluvium may be overlain by eolian deposits in this area (Topper et al. 2003). Cores collected to depths of about $9 \mathrm{~m}(29.5 \mathrm{ft})$ at the site consisted of a fining upward sequence of sands \pm gravel to silty-sand and 
silty-clays (CDLE 2017). Site features and OIP log locations are provided on the site map (Fig. S5).

\section{Field study procedures}

OIP logging was performed at the three field sites following the standard operating procedure for the OIP system (Geoprobe 2017). Historical soil and groundwater sample analytical data were used to guide the selection of OIP log locations at each site. Prior to running each OIP log on-site, and at the end of the day, quality assurance tests were performed on the optical and EC systems. A simple test jig that is designed with two different resistors was placed across the EC dipole on the probe as the EC test window was viewed on-screen. The EC response had to be within the $\pm 10 \%$ window of the expected conductance values for each resistor to pass the QA test before logging could proceed. The optical system was QA tested using cuvettes containing products of interest (e.g., diesel, motor oil). Images of the products were captured, analyzed and saved to file. If the \%AF fell below the expected range for a product, system maintenance or corrective measures were conducted. Next the optical system was tested with a "black box" to verify a dark background was achieved (no fluorescent contamination on the window or inside the optical cavity). Then, a test image was viewed under visible light to verify camera focus and color were correct. The QA data and images were saved with the log file for later review/reporting. Once the QA tests were passed logging could begin. While logging the optical system power and camera frame rate were monitored on-screen to assure that the optical system was operating properly as the log was obtained. These QA data streams are saved in each log file.

During each of the field studies reported here a direct push (DP) machine was used to advance the OIP probe into the subsurface at a rate of approximately $20 \mathrm{~mm} / \mathrm{s}(\sim 4 \mathrm{ft} /$ min) using both static weight of the machine and percussion with the hydraulic hammer as required. A drive cushion (Geoprobe ${ }^{\circledR}$ MN 221775) was typically placed between the top of the OIP tool string and the hydraulic hammer on the DP machine to minimize wear and potential damage to the OIP probe, especially during near surface advancement. Surface pavements were pre-probed, drilled or cored to a depth of about $60 \mathrm{~cm}(2 \mathrm{ft})$ or more before the OIP probe was placed in the borehole for advancement. All utilities were properly cleared before any probing/logging activities were started. Typically, the OIP probe was pushed into the pre-probed hole until the optical window bisected the ground surface (zero depth). The "trigger" icon on the software screen was then turned on, and any downward movement of the tool string (retraction of the string potentiometer) was recorded as depth in the log.

The OIP probe was typically advanced with $38 \mathrm{~mm}$ (1.5in.) or $44 \mathrm{~mm}$ (1.75-in.) diameter drive rods that are about
$1.25 \mathrm{~m}$ (4 ft.) or $1.5 \mathrm{~m}$ (5 ft.) in length. When logging the field crew stops advancement incrementally to add the next drive rod to the tool string. When advancement is stopped, the acquisition software automatically captures a still image in both UV and visible light that is saved to the log file. The $\mathrm{EC}$ and \% AF logs were viewed on-screen along with the images of induced fluorescence as the probe was advanced. At depths of interest probe, advancement was halted to capture and save additional still images in UV and visible light. Logging was stopped at the desired depth (or refusal), and then the OIP probe and tool string were retracted with a simple rod grip system. A hard rubber "rod wiper" was used to remove gross soil and contaminants from the rods and probe as they were recovered. All OIP borings were properly abandoned in accordance with local regulatory requirements.

UVOST logs were run at the Michigan UST site with a DP machine prior to obtaining the OIP logs. As briefly discussed above, the UVOST system uses a fiber optic line to connect an up-hole nitrogen laser to the downhole sapphire window. A second fiber optic line returns any fluorescent light generated in the formation to a spectrophotometer, optical multi-channel analyzer and data acquisition system at the surface. The UVOST system reports fluorescence intensity based on response compared to a hydrocarbon fuel mix (called the Reference Emitter/RE) which is tested before each $\log$. Fluorescence intensity is reported as \%RE on the $\log$. Downhole fluorescence can be greater than that measured from the RE so log results can be above $100 \%$ in some cases. Additional information regarding the UVOST system and reporting of \% RE and waveform analysis is available (St. Germaine 2011, 2012). The LIF locations at the Michigan site were marked when completed, and the OIP logs were conducted shortly after the LIF logging was finished. The OIP logs were run with a direct push machine within $0.5-1.5 \mathrm{~m}$ of the LIF locations using the procedures described above. A total of 37 colocated OIP logs were obtained in the 3-day field effort. The site map (Fig. S3) shows the LIF log locations and site features.

At the Iowa UST site, OIP logging was performed as described above using a direct push machine to advance the probe to about $9 \mathrm{~m}(27 \mathrm{ft})$ depth. A total of $18 \operatorname{logs}$ were obtained in about 2 days. After logging was completed, the team also collected continuous soil cores with the DT22 sampler (Geoprobe 2013; ASTM 2017d) adjacent to four selected OIP log locations. The site geologist performed visual/manual soil classification based on the visual-manual method (ASTM 2017f) and conducted field screening of core samples on-site using a handheld photoionization detector (PID) (Mini-RAE model 3000). Samples from each $30 \mathrm{~cm}(1 \mathrm{ft})$ interval of core were placed in ziplock bags and allowed to equilibrate at ambient temperature for 15-30 $\mathrm{min}$ before field screening with the PID. Selected results of the visual-manual soil classification and PID field screening are 
summarized (Table S2). OIP log and soil core locations are plotted on the site map (Fig. S4).

OIP logs were obtained at the Colorado UST site using the procedures outlined above at 50 locations to depths of about $10 \mathrm{~m}(30 \mathrm{ft})$. Continuous soil cores were taken adjacent to selected log locations using the DT22 dual tube soil sampling system (Geoprobe 2013; ASTM 2017d). Targeted samples based on PID field screening and OIP log results were submitted for laboratory analyses. Log and soil core locations are depicted on the site map (Fig. S5). The soil samples were analyzed for benzene, toluene, ethylbenzene and xylene (BTEX) and total volatile petroleum hydrocarbons (TVPH) using EPA Method 8260B (EPA 2014a), and total extractable petroleum hydrocarbons (TEPH) analysis was performed by EPA Method 8015B (EPA 2014b). The analytical results for selected samples are summarized for review (Table S3).

\section{Field study results}

The information below briefly summarizes typical results observed on-site during investigations with the UV-OIP System at the different sites in three states in the USA. Smallscale heterogeneity of LNAPL distribution in the subsurface is not unusual and often is controlled by subtle changes in grain size distribution, porosity and permeability (ITRC 2009a). This natural heterogeneity can influence comparison of different field methods at the meter and sub-meter scale in the subsurface.

Results from three of the paired UVOST and UV-OIP logs at the Michigan site are provided for review (Fig. 6). In the three logs plotted here, and in the majority of the paired logs obtained, the beginning and ending depth of fuel fluorescence in the subsurface is very similar, typically within about $30 \mathrm{~cm}(1 \mathrm{ft}$ ) depth (Table S4). The exact magnitude of the UV-OIP \%AF and the UVOST \%RE are typically similar but show some variability. At some locations and depths the \% AF is higher, while at other depths and locations the $\% \mathrm{RE}$ is higher. These variances are probably due primarily to small-scale heterogeneity of the LNAPL distribution in the formation. Some of the variability observed may be due to differences in the specific technology used and methods of quantitation. Additional research would be required to fully address the variances observed in fluorescence between the two methods at the field scale.

One of the UV-OIP logs from the Iowa UST site is plotted along with the USCS soil type and results from handheld PID field screening from the adjacent soil boring (Fig. 7). Plotting the PID field screening results for soil samples over the OIP \%AF log reveals that the highest PID responses correlate with the two peaks observed in the \% $\mathrm{AF} \log$. Both the $\mathrm{PID}$ and \% AF logs show a bifurcation of maximum response at approximately the same depths. Lower PID responses do occur across intervals where product concentration was too low (dissolved/dispersed) to yield any UV-induced fluorescence. A still image from this log captured at a depth of $5.01 \mathrm{~m}$ clearly shows bright fuel fluorescence from fuel covering much of the image area (77.5\% AF) at the maximum OIP log response which correlates with high PID readings.

Based on the visual-manual soil classification (ASTM 2017f) performed on-site in Kalona, Iowa lean clays (CL) were observed to dominate the upper 3-4 $\mathrm{m}$ of the local formation (Fig. 7). The lean clays exhibited the highest bulk formation EC at the site, generally exceeding $80 \mathrm{mS} / \mathrm{m}$
Fig. 6 Overlays of three colocated logs run with the UV-OIP system and the UVOST system at the Michigan UST site. Note the similarities in fluorescence magnitude and vertical extent of fluorescence response
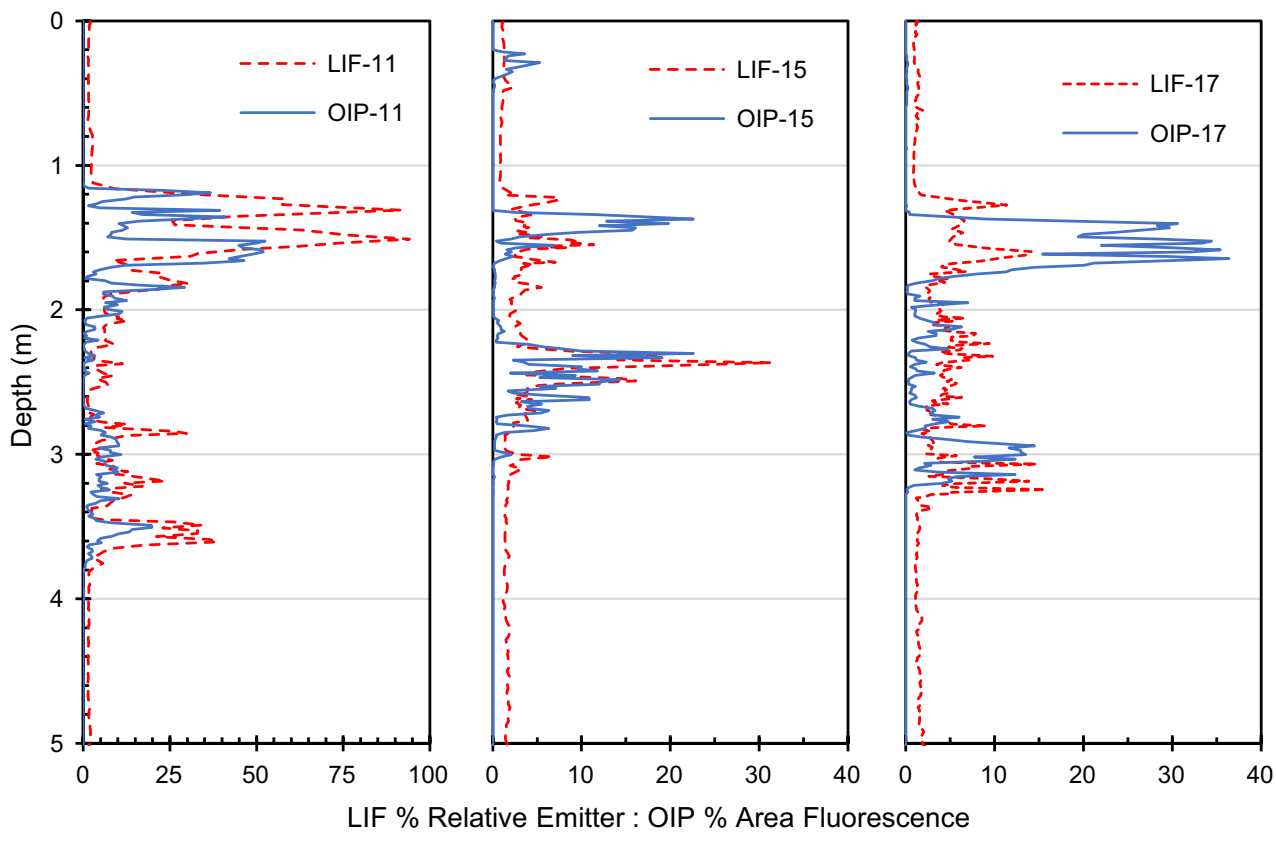


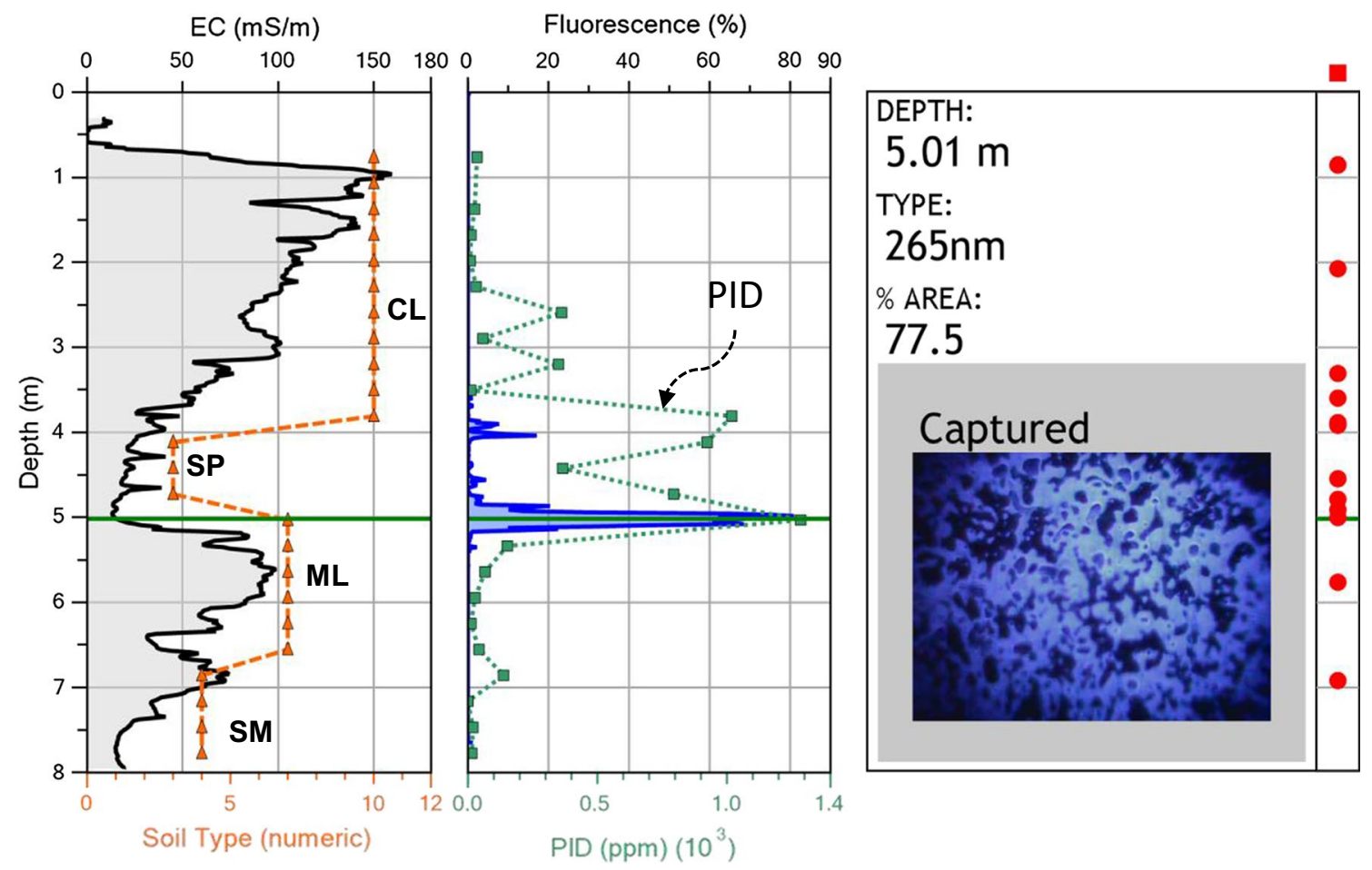

Fig. 7 Log OIP07 obtained at the Iowa UST site. USCS soil classification (ASTM D2488) plotted over bulk formation EC log on the left panel. Numeric values used for USCS soil types are: lean clay $=C L=10$, sandy silt $=M L=7$, well graded sand with silt \pm gravel $=\mathrm{SM}=4$, and poorly graded sand with silt and gravel $=\mathrm{SP}=3$. Second panel, field screen PID log plotted over the

response. A saturated, poorly graded sand (SP) layer usually occurred below the upper clays at depths between approximately 4 to $5 \mathrm{~m}$ and exhibited lower bulk formation EC, ranging between about 10 to $50 \mathrm{mS} / \mathrm{m}$ across the site. A sandy silt (ML) zone lies between approximately 5-7 m depth in this $\log$ and typically exhibited a bulk formation EC between approximately $50-80 \mathrm{mS} / \mathrm{m}$ across the site. A deeper zone of saturated, silty sand \pm gravel $(\mathrm{SM})$ was present below approximately $7 \mathrm{~m}$ at this location and also exhibited bulk formation EC ranging between about 10 to $50 \mathrm{mS} / \mathrm{m}$ across the site. These results indicate that the bulk formation EC of the saturated sandy materials at this site generally ranged between approximately 20 to $70 \mathrm{mS} / \mathrm{m}$, decreasing with increasing sand and/or gravel content. The EC log was found to correlate well with the USCS boring $\log$ at this location and the other three locations that were cored. Targeted coring at selected locations should be conducted to confirm EC log interpretation as the presence of salts or elevated dissolved solids, and other variables can impact the EC log response (McCall et al. 2014, 2017).

A simplified cross section of the Iowa site based on the EC and \%AF logs (Fig. 8) may be used to assist with developing a high resolution conceptual site model (CSM) for
UVOIP \%AF log. Right panel is still image of UV-induced fluorescence (blue) of fuel in formation matrix (dark) captured at a depth of $5.01 \mathrm{~m}$ during this $\log$. Red dots on far right indicate depths where still images were captured. All saved log images and still images may be reviewed in the log viewing software

LNAPL distribution. Comparing results from the soil boring $\operatorname{logs}$ to the EC $\log$, it was evident that when the bulk formation EC dropped below about $80 \mathrm{mS} / \mathrm{m}$ the sand \pm gravel content and permeability of the formation increased. The $80 \mathrm{mS} / \mathrm{m}$ level was used to define a boundary (or contact) between the higher EC/lower permeability zones and lower EC/higher permeability zones of the formation. Based on this EC defined contact the higher permeability (sandy) zones of the formation are outlined and shaded in light blue on the cross section. The shading reveals that an upper and lower sandy zone are separated by a sandy silt (ML) layer across most of the cross section. However, the intervening sandy silt layer pinches out near the northern edge of the site area (between logs OIP8 and OIP15). The \% AF logs also are plotted on the cross section, shaded dark blue. It becomes apparent that the LNAPL is primarily located in the upper sandy zone (SP) of higher permeability (lower EC) across the site. This clearly indicates that this low EC/high permeability zone is the primary migration pathway for LNAPL at this facility. Note that almost all of the LNAPL detected is about $1.5-2 \mathrm{~m}$ below the current water level at this site. Additionally, significant fuel fluorescence was observed in the lower sandy zone only at two logs in 


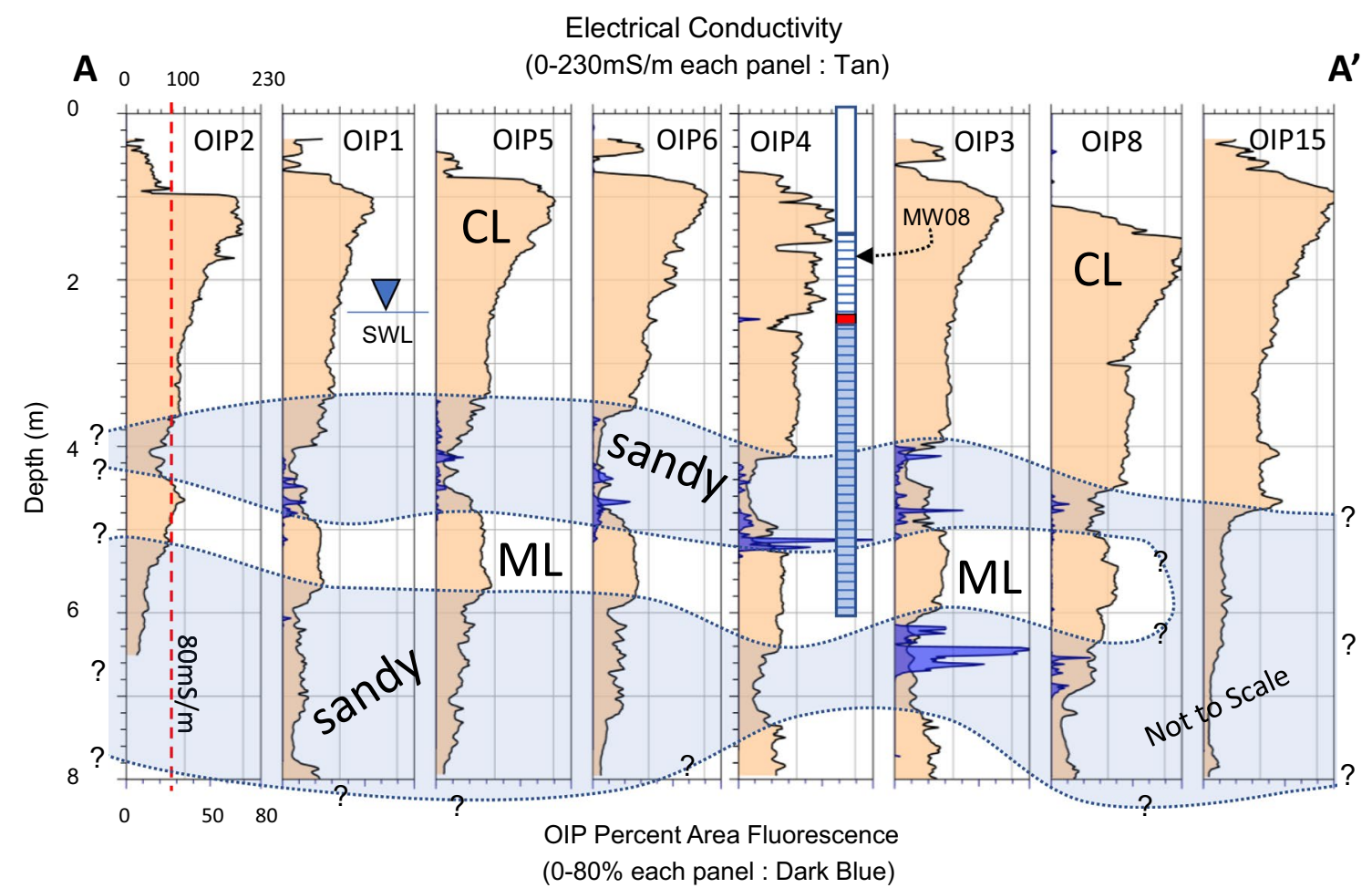

Fig. 8 South-north cross section $\left(\mathbf{a}-\mathbf{a}^{\prime}\right)$ at the Iowa UST site. Electrical conductivity is shaded tan and OIP percent area fluorescence is shaded dark blue. Light blue shading is applied to define the sandy zones in the local formation. Red =LNAPL in well. Note that upper sandy zone is the primary migration pathway for LNAPL at this site. $\mathrm{SWL}=$ static water level $=2.4 \mathrm{~m}$. MW08 $=$ monitoring well located

this cross section, OIP3 and OIP8, near the former pump island (Fig. 8 and Fig. S4). A monitoring well (MW08) is located between the OIP3 and OIP4 logs and is screened from approximately 1.5 to $6 \mathrm{~m}$ below grade. Occasionally, free product has been reported floating in this well and the nearby $\log$ (OIP4) detected fluorescence in a sandy lens in the formation near the static water level (currently $\sim 2.4 \mathrm{~m}$ depth). It appears that the floating product in well MW08 originated from the permeable zone deeper in the formation. The municipal drinking water line is about $1-2 \mathrm{~m}$ laterally from this location (Fig. S4), and the presence of free product here may increase human health risks. These conditions clearly indicate that EC and OIP logging should be performed prior to well construction to minimize the potential for vertical movement of LNAPL to other zones of the formation through incorrectly designed wells. This will be especially important under confined or semi-confined conditions as observed at this and many other sites.

About 50 OIP logs were run at the Colorado UST site. At a few locations, continuous soil coring was conducted adjacent to the OIP logs (Geoprobe 2013; ASTM 2017b). The soil cores were screened by handheld PID on-site, and selected intervals were sampled for BTEX, TVPH and between $\operatorname{logs}$ OIP4 and OIP3, screened approx. 1.5-6 m $(5-20 \mathrm{ft})$ below ground surface. $\mathrm{CL}=$ lean clay \pm sand, $\mathrm{ML}=$ silt \pm sand. See Figure S4 for site map with cross section line and well location. Logs shown equally spaced on the cross section, not equally spaced on the ground, not to scale

TEPH laboratory analysis (Table S3). BTEX compounds require a higher energy-shorter wavelength UV light source than the UVOST 308-nm laser system to induce fluorescence. While the 275-nm UV LED OIP system will induce fluorescence in the BTEX compounds they fluoresce in the UV range (Karlitschek et al. 1998; Bloch et al. 1998) and are not detectable by the OIP CMOS camera or the UVOST system (St. Germaine 2011). Additionally, the chain and branched hydrocarbons in the TVPH range do not fluoresce. So, there will be no fluorescence generated by these analytes while OIP logging [same condition for the UVOST system (St. Germaine 2011)]. Due to this behavior, only the TEPH sample results are used for comparison to the OIP $\%$ AF log results for two locations (Fig. 9). Samples collected from the same intervals where the OIP log shows high \%AF peaks have elevated TEPH results. The UV-OIP fluorescence images captured at these sample depths give visual confirmation of fuel fluorescence in the formation (Fig. 9). Soil samples also were collected about a meter beneath the zones where significant fluorescence was observed at each of these locations. At the CO39a log location, the \% AF at $6.5 \mathrm{~m}$ depth had returned to baseline $(0 \% \mathrm{AF})$ reading. The soil sample collected at this location and depth reported 

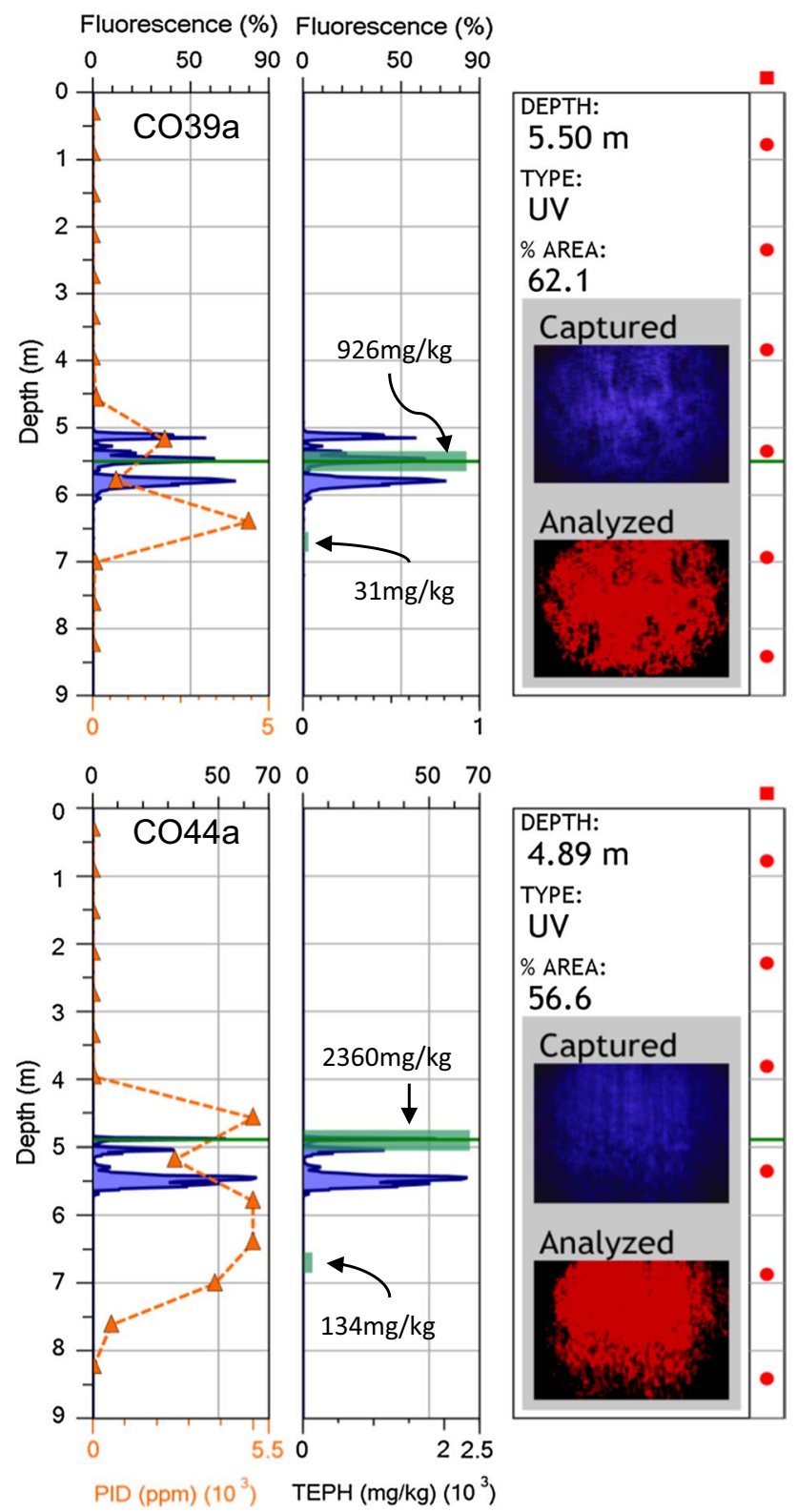

Fig. 9 Logs CO39a and CO44a from the Colorado UST site with PID field screening data (orange triangles) and soil sample results for total extractable petroleum hydrocarbons (TEPH) data (green bars). OIP $\% \mathrm{AF} \log$ in blue. Both the captured fluorescence image and the analyzed image showing area defined as fuel fluorescence are provided. Image depth indicated by horizontal green line and reported in top right panel

only $31 \mathrm{mg} / \mathrm{kg}$ TEPH, at or below the detection level for the UV-OIP system (OIP image dark). Interestingly, at log location CO44a a sample from about $6.5 \mathrm{~m}$ depth (where the OIP is reporting baseline fluorescence levels) was found to contain only $134 \mathrm{mg} / \mathrm{kg}$ TEPH but much higher concentrations of the BTEX and non-fluorescent TVPH compounds (Table S3). The lack of fluorescence here is appropriate as discussed above. Therefore, investigators should note that elevated concentrations of compounds not detectable by the OIP or UVOST system, but of concern (e.g., BTEX), may still be present. In these situations, logging with the membrane interface probe (MIP) will better define the extent of the volatile contaminants (McCall et al. 2014; ASTM 2017g) not detectable with current fluorescence logging tools.

Similar to the Iowa UST facility, a simplified cross section was created for the Colorado UST site (Fig. 10). This cross section trends approximately north-south along the long axis of the LNAPL plume as defined by the OIP logs (Fig. S5). Again, it is apparent that the LNAPL is moving through the subsurface in a lower EC/higher permeability sandy zone of the alluvial formation. This is primarily below a high EC, lower permeability layer that extends across the site. The base of the low permeability layer is marked with a heavy dashed line on the cross section. Note that the LNAPL plume is again primarily beneath the current water level in the formation, similar to the observation at the Iowa UST facility. The primary source area at this facility appears to be near the OIP26 log as seen by the large vertical interval of elevated \% AF at this location. Three monitoring wells situated near OIP logs are depicted on the cross section with screen intervals and water levels. The water levels were measured at the time the OIP investigation was performed. Comparing the water levels to a reference elevation line $(1286 \mathrm{~m})$ highlighted on the cross section suggests that the LNAPL is actually migrating against the hydraulic gradient. Earlier water level data show that the groundwater level was deeper in the past and that the gradient has changed over time (CDLE 2017).

Interestingly, the LNAPL was found to be migrating away from source areas at all three sites beneath the ambient water table, evidently a common occurrence. At all three sites confining or semi-confining hydraulic conditions persisted with an overlying, fine-grained facies and underlying, saturated, coarser-grained facies. Regardless of the mechanism(s) of how the LNAPL was emplaced below the water table, once there, lateral movement in the coarser-grained zones may then be driven by hydraulic gradient or gravity/density driven preferential movement essentially up-dip beneath fine-grained confining layers (U.S. EPA 2000).

\section{Future OIP developments and potential applications}

Currently an OIP system with a green wavelength LED is under development that should prove useful for the investigation of coal tars and creosote as well as some heavy fuel oils. Initial tests with an infrared (IR) LED have also been conducted. Some initial tests also have been conducted to evaluate the use of the UV OIP system for detection of common tracer dyes in the subsurface (personal communication, 


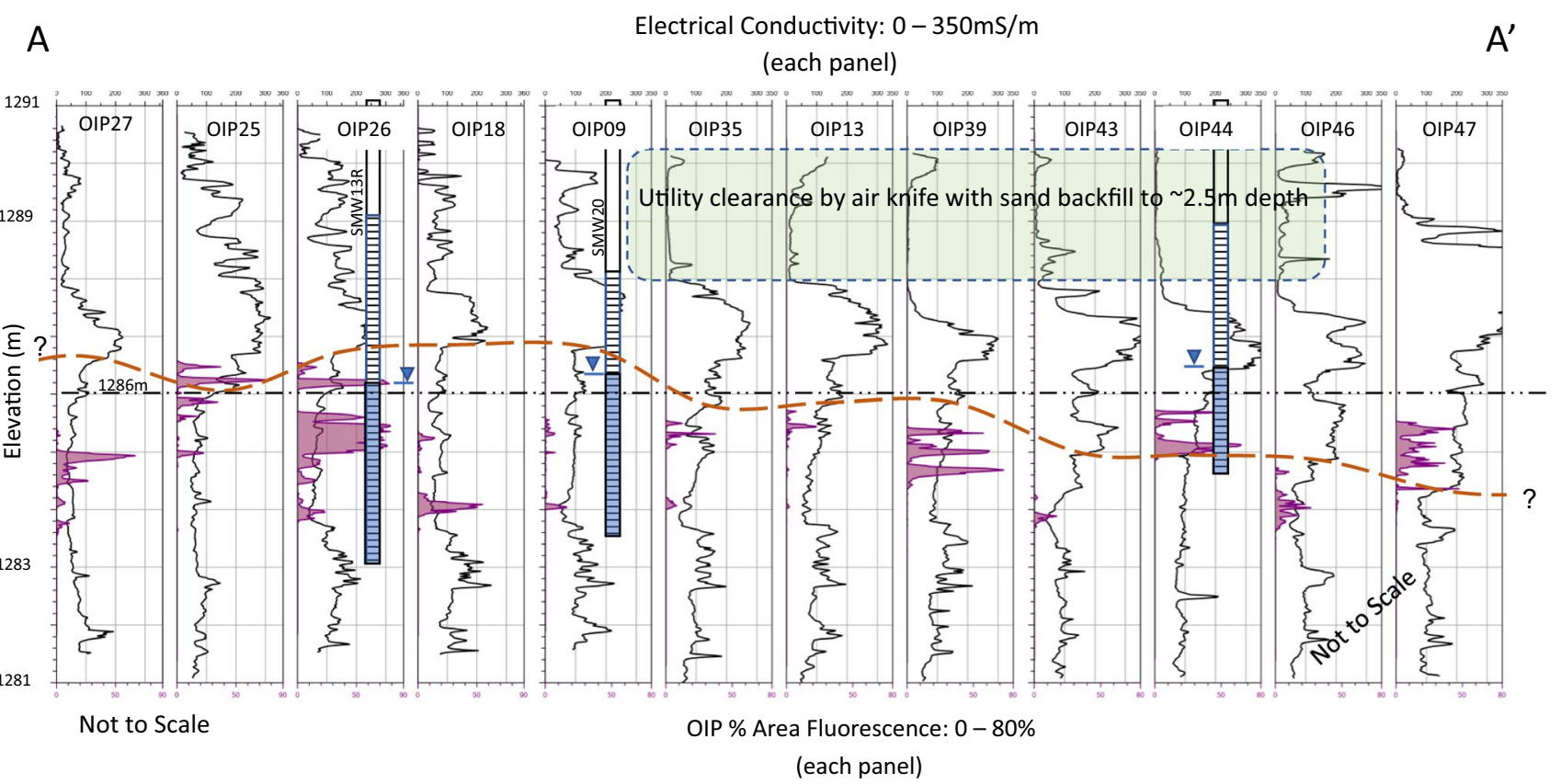

Fig. 10 Approximately north-south $\left(\mathbf{a}-\mathbf{a}^{\prime}\right)$ cross section for the Colorado UST site, see site map (Fig S4) for location. This overlay of EC (black line/white fill) and \% AF logs (purple line and fill) help to demonstrate that the LNAPL is primarily migrating within lower EC/ higher permeability material below an overlying high EC/lower per-

Markus Reischer at NIRAS, Denmark, December, 2017). This application could prove useful for evaluation of porosity and permeability and potentially for monitoring tracer tests or the distribution of remediation fluids (spiked with fluorescent dyes) injected into the subsurface. Attempts have also been made to use other downhole optical tools to assess grain size distribution (Raschke and Hryciw 1997; Lee et al. 2008), and this may be a possibility with the visible light OIP images. Initial testing of a combined OIPHPT (hydraulic profiling tool) also has been conducted. The HPT injection pressure log provides useful information about hydrostratigraphy and formation permeability to better define potential contaminant migration pathways (McCall et al. 2009, 2014, 2017).

\section{Conclusions}

Determining the presence and distribution of petroleum LNAPLs in the subsurface is a widespread and challenging problem for the geo-environmental industry. The OIP probe and system provide a new tool and new technology to assist with defining both the presence and distribution of many fuel LNAPLs in unconsolidated materials. The images of UV-induced fuel fluorescence provide not only confirmation that LNAPLs are present, but also visual information meability zone. Bottom of higher EC/lower permeability zone set at $150 \mathrm{mS} / \mathrm{m}$ and indicated by heavy, orange dashed line. The $1286 \mathrm{~m}$ elevation line marked by dash-dot-dot black line. Logs plotted at elevation. Logs plotted as equally spaced in this simplified cross section, not equally spaced on the ground, not to scale

not previously available about the distribution and behavior of LNAPLs in the formation matrix. Additionally, images of LNAPL fluorescence and visible light images can provide information about the formation grain size and texture. This information should help further the understanding of LNAPL behavior in the subsurface.

Bench tests with the OIP probe using commercially available regular unleaded gasoline, on-road diesel fuel and Bemidji crude oil were used to evaluate the performance of the OIP system for detecting petroleum LNAPLs under near ideal conditions. The initial detection of fluorescence for diesel fuel and unleaded gasoline occurred just below or above the $100 \mathrm{mg} / \mathrm{kg}$ (ppm) level (respectively) in the bench tests. Both products provided a log-linear response of \% $\mathrm{AF}$ versus concentration over about an order of magnitude concentration range. The crude oil produced about $10 \% \mathrm{AF}$ at the $50 \mathrm{mg} / \mathrm{kg}$ level and provided a rough log-linear response over the entire concentration range tested (at least 4 orders of magnitude). The bench test results confirm that the OIP system should be an effective tool for detection of many petroleum fluids in the subsurface. The fluorescence observed in complex and heterogeneous natural soils and sediments from weathered products may differ significantly from that observed in the bench tests under idealized conditions.

The results of recent OIP investigations for the presence and distribution of petroleum fuel LNAPLs at three UST 
sites in different states in the USA were reviewed. At a site in Michigan OIP logs were run within a couple of meters of more than 30 recently completed UVOST logs. Side-by-side comparison of the OIP \%AF to the UVOST \%RE for three of the logs was provided to demonstrate that both methods defined similar fluorescence responses and depth intervals for the distribution of LNAPL across the site.

The use of the common PID field screening practice for continuous soil cores and also visual-manual soil classification was performed adjacent to four OIP logs at a UST facility in Kalona, Iowa. Plotting of the PID log over the OIP \%AF log demonstrated good correlation between the two methods. The advantage of the OIP logging here is that no samples have to be collected to obtain the \%AF logs. This not only reduces the physical level of effort for the investigation but also reduces the potential for worker exposure to hazardous contaminants as well as reducing the cost of dealing with investigation derived waste.

Investigation at the third site in Colorado was coupled with continuous soil coring at targeted locations. Analyses of selected soil samples for BTEX, TVPH and TEPH were conducted using US EPA standard analytical methods. Comparing the sample analytical results at two of the locations indicated that the OIP \% AF logs correlated well with the total extractable petroleum hydrocarbon (TEPH) analyses. On the other hand, it was observed that at least at one location the presence of elevated BTEX and TVPH levels were not detected by fluorescence logging in the absence of significant TEPH. This distinction is important and occurs because the UV fluorescence of the BTEX compounds is not detectable with the OIP CMOS camera. The lack of BTEX detection is also true for all other fluorescence logging tools currently in use and indicates that logging with the membrane interface probe (MIP) under these conditions may be needed.

Simplified cross sections were prepared for both the Iowa and Colorado sites where the \% AF was plotted over the bulk formation EC log. EC log interpretation was confirmed with targeted soil coring at these sites. At both sites, the cross sections revealed that fuel LNAPLs were migrating in low EC (higher permeability) zones of the formation well beneath the ambient water table as defined by nearby monitoring wells. This situation appears to be a common occurrence at many LNAPL sites. Perhaps excess LNAPL head pressure exacerbated by intermittently pumping/supply lines, leaking beneath pavement-confined areas, encouraged movement of LNAPL below the water table, which then migrated laterally.

In summary, the DP advanced OIP probe should prove to be a useful tool at many sites for high resolution site characterization of common petroleum LNAPLs in unconsolidated materials. The log data can be used to guide targeted sampling/analysis of soil or groundwater to confirm log results and reduce the overall level of effort and project costs. The images of UV-induced fluorescence can be used to verify the presence of the contaminants and evaluate their distribution in the formation matrix at the millimeter scale. This photographic information may enhance the understanding of LNAPL behavior in the subsurface. The visible light images should help with interpretation of lithology and formation characteristics. The \%AF logs along with tandem EC logs [and later tandem hydraulic profiling tool (HPT) logs] will assist with the development of more detailed and accurate CSMs to help manage these sites and achieve remedial goals more effectively.

Acknowledgements The authors wish to express their appreciation to Dennis Grimm, former owner of the facility in Kalona, Iowa for providing site access and Impact $7 \mathrm{G}$ for providing the DP machine, operator and assistant for OIP logging and sampling at that facility. We also want to thank Stock Drilling for providing the DP machine and machine operator for the OIP logging activities at the facility in Michigan and Compliance Inc., Brighton, Michigan for their assistance in coordinating the effort at the Michigan facility.

Open access This article is distributed under the terms of the Creative Commons Attribution 4.0 International License (http://creativeco mmons.org/licenses/by/4.0/), which permits unrestricted use, distribution, and reproduction in any medium, provided you give appropriate credit to the original author(s) and the source, provide a link to the Creative Commons license, and indicate if changes were made.

\section{References}

Agoston MK (2005) Computer graphics and geometric modeling: implementation and algorithms. Springer, London, pp 300-306. ISBN: 1-85233-818-0. See also https://en.wikipedia.org/wiki/ HSL_and_HSV\#Joblove

American Society of Testing and Materials (ASTM) (2017a) E1739 standard guide for risk-based corrective action applied at petroleum release sites. ASTM International, West Conshohocken. www.astm.org

ASTM (2017b) E2531 development of conceptual site models and remediation strategies for light nonaqueous-phase liquids released to the subsurface. ASTM International, West Conshohocken. www.astm.org

ASTM (2017c) D6187 standard practice for cone penetrometer technology characterization of petroleum contaminated sites with nitrogen-laser induced fluorescence. ASTM International, West Conshohocken. www.astm.org

ASTM (2017d) D6282 standard guide for direct push soil sampling for environmental site characterization. ASTM International, West Conshohocken. www.astm.org

ASTM (2017e) E2856 standard guide for estimation of LNAPL transmissivity. ASTM International, West Conshohocken. www.astm. org (active)

ASTM (2017f) D2488 standard practice for description of soils (visualmanual procedure). ASTM International, West Conshohocken. www.astm.org

ASTM (2017g) D7352 standard practice for direct push technology for volatile contaminant logging with the membrane interface probe (MIP). ASTM International, West Conshohocken. www.astm.org 
Bain HF (1895) Geology of Washington County. In: Iowa geological survey annual report, vol 5, pp 113-173. http://ir.uiowa.edu/igsar /vol5/iss $1 / 4$

Berlman IB (1965) Handbook of fluorescence spectra of aromatic molecules. Academic Press, New York

Bloch J, Johnson B, Newbury N, Germaine J, Hemond H, Sinfield J (1998) Field test of a novel micro-laser based probe for in situ fluorescence sensing of soil contamination. Appl Spectrosc 52(10):1299-1304

Bujewski G, Rutherford B (1997) The rapid optical screening tool (ROSTTM) laser-induced fluorescence (LIF) system for screening of petroleum hydrocarbons in subsurface soils. Innovative technology verification report. National Exposure Research Laboratory, Characterization Research Division, U.S. EPA

Christy TM (1996) Drivable permeable membrane sensor for detection of volatile compounds in soil. In: Proceedings of the 1996 national outdoor action conference, Las Vegas Nevada. National Ground Water Association, Columbus

Christy CD, Christy TM, Wittig V (1994) A percussion probing tool for the direct sensing of soil conductivity. Technical paper no. 94-100. Kejr, Inc., Salina

Colorado Department of Labor and Employment (CDLE) (2017) Site characterization report: oil and public safety ID No. 5313. Division of Oil and Public Safety, Remediation Section, Denver

Compliance Inc. (2016) Technical Memorandum: Darwin's truck and auto service 11535 US-12, Brooklyn, Michigan. Prepared for the Michigan Department of Environ. Quality, Jackson, MI, USA by Compliance Inc., Traverse City

Contaminated Land: Applications in Real Environments (CLAIRE) (2014) An illustrated handbook of LNAPL transport and fate in the subsurface. CLAIRE, London. ISBN: 978-1-905046-24-9

Cooke M (2010) Going deep for UV sterilization LEDs. In: Semiconductor today, compounds \& advanced silicon, vol 5, issue 3. www.semic onductor-today.com

Dixon JM, Taniguchi M, Lindsey JS (2005) PhotochemCAD 2. A refined program with accompanying spectral databases for photochemical calculations. Photochem Photobiol 81:212-213

Geoprobe (2013) Geoprobe ${ }^{\circledR}$ DT22 dual tube soil sampling system, continuous core soil sampler. Standard operating procedure, technical bulletin no. MK3140. Kejr Inc., Salina. www.geoprobe.com

Geoprobe (2017) Geoprobe ${ }^{\circledR}$ optical imaging profiler (OIP): standard operating procedure. Kejr, Inc., Salina. www.geoprobe.com

Goodrich JE (2017) Tier 3 risk assessment, former Denny's 66/Grimm oil, Kalona, Iowa. LUST No. 7LTY57. VJ Engineering, Coralville

Interstate Technology and Regulatory Council (ITRC) (2009a) Evaluating natural source zone depletion at sites with LNAPL. LNAPL-1. ITRC LNAPLs Team, Washington. www.itrcweb.org

Interstate Technology and Regulatory Council (ITRC) (2009b) Evaluating LNAPL remedial technologies for achieving project goals. LNAPL2. ITRC LNAPLs Team, Washington. www.itrcweb.org

Iowa Department of Natural Resources (IDNR) (2015) Tier 2 site cleanup report: leaking underground storage tank site assessment, LUST No. 7LTY57

Iowa Department of Natural Resources (IDNR) (2017) Tier 2 site cleanup report guidance: site assessment of leaking underground storage tanks using risk-based corrective action. Underground Storage Tank Section, IDNR, Des Moines, Iowa, USA. http://www.iowadnr.gov/ Environmental-Protection/Land-Quality/Underground-StorageTanks/Leaking-Underground-Tanks/LUST-Site-Assessment/Tier-2

Karlitschek P, Lewitzka F, Bünting U, Niederkrüger M, Marowsky G (1998) Detection of aromatic pollutants in the environment by using UV-laser-induced fluorescence. Appl Phys B Lasers Opt 67:497-504

Kram ML, Keller AA, Massick SM, Laverman LE (2004) Complex NAPL site characterization using fluorescence part 1: selection of excitation wavelength based on NAPL composition. Soil Sediment Contam 13:103-118. https://doi.org/10.1080/10588330490278039
Lakowicz JR (1999) Principles of fluorescence spectroscopy, 2nd edn. Kluwer Academic/Plenum Publishers, New York

Lee DS, Elsworth D, Hryciw R (2008) Hydraulic conductivity measurement from on-the-fly uCPT sounding and from VisCPT. J Geotech Geoenviron Eng 134(12):1720-1729

McCall W, Nielsen DM, Farrington SP, Christy TM (2006) Use of direct-push technologies in environmental site characterization and ground-water monitoring, chapter 6. In: Nielsen DM (ed) Practical handbook of environmental site characterization and ground-water monitoring, 2nd edn. Taylor \& Francis, Boca Raton

McCall W, Christy TM, Christopherson T, Isaacs H (2009) Application of direct push methods to investigate uranium distribution in an alluvial aquifer. Groundw Monit Remediat 29(4):65-76

McCall W, Christy TM, Pipp D, Terkelsen M, Christensen A (2014) Field application of the combined membrane-interface probe and hydraulic profiling tool (MiHPT). Groundw Monit Remediat 34(2):85-95

McCall W, Christy TM, Evald MK (2017) Applying the HPT-GWS for hydrostratigraphy, water quality and aquifer recharge investigations. Groundw Monit Remediat 37(1):78-91

Mercer JW, Cohen RM (1990) A review of immiscible fluids in the subsurface: properties, models, characterization and remediation. $\mathrm{J}$ Contam Hydrol 6:107-163

Moynihan T (2011) CMOS is winning the camera sensor battle, and here's why. PC World, London

Naval Facilities Engineering Command (NAVFAC) (2017) Environmental restoration: complex challenges at light non-aqueous phase liquid sites. U.S. Department of Defense, NAVFAC. ESAT N62583-11-D-0515

Raschke SA, Hryciw RD (1997) Grain-size distribution of granular soils by computer vision. Geotech Test J 20(4):433-442. www.astm.org

St. Germaine R (2011) Laser-Induced Fluorescence Primer. In: Applied NAPL science review, vol 1, no 9. http://www.h2altd.com/wp-conte nt/uploads/2011/10/ANSR-v1i9.pdf

St. Germaine R (2012) Laser-induced fluorescence primer II. In: Applied NAPL science review, vol 2, no 5. http://www.h2altd.com/wp-conte nt/uploads/2012/07/ANSR-v2i5.pdf

Suthersan S, Koons B, Schnobrich M (2015) Contemporary management of sites with petroleum LNAPL. Groundw Monit Remediat 35(1):23-29

Topper R, Spray KL, Bellis WH, Hamilton JL, Barkman PE (2003) Ground water atlas of Colorado. Special Publication, chapter 5, vol 53. Colorado Geological Survey, Denver

U.S. EPA (1986) Interim report: fate and transport of substances leaking from underground storage tanks: vol I-technical report (see Table 5-4). Prepared by Camp Dresser \& McKee, Inc. under contract no. 68-01-6939

U.S. EPA (1990) RCRA orientation manual, 1990 Edition. Office of Solid Waste, Washington. EPA/530-SW-90-036

U.S. EPA (1997) Expedited site assessment tools for underground storage tank sites: a guide for regulators. EPA 510-B-97-001

U.S. EPA (2000) Innovations in site characterization: geophysical investigation at hazardous waste sites (see Kansas UST Site, pp 65-77). Office of Solid Waste and Emergency Response. EPA542-R-00-003. www.cluin.org

U.S. EPA (2014a) Method 8260B: volatile organic compounds by gas chromatography/mass spectrometry (GC/MS). In: Test methods for evaluating solid waste: physical/chemical methods compendium (SW-846) Update V, Revision B

U.S. EPA (2014b) Method 8015B: total petroleum hydrocarbons (TPH) as gasoline and diesel (Revision 2, December 1996). In: Test methods for evaluating solid waste: physical/chemical methods compendium (SW-846) Update V, Revision B

U.S. Silica Company (2015) U.S. Silica Company safety data sheet: silica sand or ground silica; crystalline silica (quartz). U.S. Silica Company, Frederick 
White J (2015) Getting to that high hanging fruit: building consensus through corrective action conferences. LUST Line Bull 78:13-14. New England Interstate Water Pollution Control Commission, Lowell. www.neiwpcc.org/lustline
Williams DE, Wilder DG (1971) Gasoline pollution of a ground-water reservoir - a case history. Ground Water 9(6):50-56 